\title{
Curcuma longa extract improves serum inflammatory markers and mental health in healthy participants who are overweight: a randomized, double-blind, placebo-controlled trial
}

Ryusei Uchio * (1), Kengo Kawasaki, Chinatsu Okuda-Hanafusa, Ryosuke Saji, Koutarou Muroyama, Shinji Murosaki, Yoshihiro Yamamoto and Yoshitaka Hirose

\begin{abstract}
Background: The dietary spice Curcuma longa, also known as turmeric, has various biological effects. Both a water extract and a supercritical carbon dioxide extract of $C$. longa showed anti-inflammatory activities in animal studies. However, the anti-inflammatory effect in humans of a mixture of these two C. longa extracts (CLE) is poorly understood. Therefore, we investigated the effect of CLE containing anti-inflammatory turmeronols on chronic inflammation and general health.
\end{abstract}

Methods: We performed a randomized, double-blind, placebo-controlled study in healthy subjects aged 50 to 69 years with overweight. Participants took two capsules containing CLE (CLE group, $n=45$ ) or two placebo capsules (placebo group, $\mathrm{n}=45$ ) daily for 12 weeks, and serum inflammatory markers were measured. Participants also completed two questionnaires: the Medical Outcomes Study (MOS) 36-Item Short-Form Health Survey (SF-36) and the Profile of Mood States (POMS) scale. Treatment effects were analyzed by two way analysis of variance followed by a $t$ test (significance level, $p<0.05$ ).

Results: After the intervention, the CLE group had a significantly lower body weight $(p<0.05)$ and body mass index $(p<0.05)$ than the placebo group and significantly lower serum levels of C-reactive protein $(p<0.05)$ and complement component $3(p<0.05)$. In addition, the CLE group showed significant improvement of the MOS SF-36 mental health score $(p<0.05)$ and POMS anger-hostility score $(p<0.05)$.

Conclusion: CLE may ameliorate chronic low-grade inflammation and thus help to improve mental health and mood disturbance.

Trial registration: UMIN-CTR, UMIN000037370. Registered 14 July 2019, https://upload.umin.ac.jp/cgi-open-bin/ctr/ ctr_view.cgi?recptno=R000042607

*Correspondence: uchio_ryusei@house-wf.co.jp

Research \& Development Institute, House Wellness Foods Corp., 3-20

Imoji, Itami, Hyogo 664-0011, Japan

(c) The Author(s) 2021. Open Access This article is licensed under a Creative Commons Attribution 4.0 International License, which permits use, sharing, adaptation, distribution and reproduction in any medium or format, as long as you give appropriate credit to the original author(s) and the source, provide a link to the Creative Commons licence, and indicate if changes were made. The images or other third party material in this article are included in the article's Creative Commons licence, unless indicated otherwise in a credit line to the material. If material is not included in the article's Creative Commons licence and your intended use is not permitted by statutory regulation or exceeds the permitted use, you will need to obtain permission directly from the copyright holder. To view a copy of this licence, visit http://creativecommons.org/licenses/by/4.0/. The Creative Commons Public Domain Dedication waiver (http://creativeco mmons.org/publicdomain/zero/1.0/) applies to the data made available in this article, unless otherwise stated in a credit line to the data. 
Keywords: Turmeric (Curcuma longa), Bisacurone, Body mass index (BMI), Turmeronol, Chronic inflammation, C-reactive protein (CRP), Complement component 3 (C3), 36-item short-form health survey (SF-36), Profile of mood states (POMS)

\section{Introduction}

Inflammation is a physiological response to infection or tissue injury that involves vasodilatation, increased vascular permeability, and recruitment of leucocytes to inflammatory tissues to eliminate pathogenic microorganisms and dead cells, with subsequent induction of tissue repair and regeneration [1]. On the other hand, chronic inflammation is a persistent inflammatory response mediated by long-lived immune and nonimmune cells that can have various undesirable effects, including tissue damage, inhibition of healing, promotion of fibrosis, and disruption of homeostasis [1, 2]. Recently, low-grade inflammation has been recognized as a state in which systemic inflammatory mediators are only slightly elevated relative to the levels seen in acute inflammation [3, 4]. This type of inflammation has not been clearly defined but it is considered to be related to aging [5], obesity [4], and an unhealthy lifestyle [6] in the absence of obvious infection or tissue injury [3]. Previous reports indicated that chronic low-grade inflammation is potentially associated with an increased risk of metabolic syndrome [7], atherosclerotic disease [8], Alzheimer's disease [9], neurodegenerative disease [2], sickness behaviors and mood disturbance [10], cancer [11], and mortality $[12,13]$.

Inflammatory markers include C-reactive protein (CRP), complements, and fibrinogen, all of which are induced by inflammatory cytokines in response to stimulation by conserved microbial structures, tissue damage signals, and metabolic stress [1, 3, 4, 14]. CRP has been frequently used as a measure of low-grade inflammation and is well known to opsonize bacteria and apoptotic cells for their clearance via the complement systems and phagocytosis [15]. Additionally, CRP has been reported to promote pro-inflammatory cytokine/chemokine production in human macrophages [16] and to increase monocytes-endothelial cell adhesion [17]. Inflammation activates complement pathways, leading to the formation of two different complement component 3 (C3) convertases: $\mathrm{C} 4 \mathrm{bC} 2 \mathrm{~b}$ in the classical and lectin pathways and $\mathrm{C} 3 \mathrm{bBb}$ in the alternative pathway. These $\mathrm{C} 3$ convertases cleave $\mathrm{C} 3$ into two fragments: C3a, an inflammatory mediator, and $\mathrm{C} 3 \mathrm{~b}$, which induces the formation of lytic membrane attack complexes for lysing targeted cells and bacteria [18]. Fibrinogen has an important role not only in the activation of the coagulation cascade but also in the promotion of inflammation by inducing cytokine production, leukocyte infiltration in inflamed tissues, and platelet aggregation [19]. High systemic levels of these inflammatory markers are well known to be associated with increased risk for chronic inflammatory diseases [2, $19,20]$. In addition, elevation of circulating levels of CRP and C3 may be associated with impaired quality of life (QOL) and mood disturbance [21-23].

Curcuma longa, also known as turmeric, is a member of the Zingiberaceae family and a traditional spice that has various physiological activities [24]. Water extracts of turmeric have antioxidant and anti-inflammatory effects [25], promote corneal wound healing [26], show antidepressant activity [27], and have an anticancer effect [28]. In addition, hot water extracts of $C$. longa were reported to prevent various chronic inflammatory diseases in animal models, including cotton pellet-induced granuloma [29], carbon tetrachloride-induced hepatitis [30], and non-alcoholic steatohepatitis [31,32], by decreasing the expression of genes coding for inflammatory cytokines and cell adhesion molecules. Supercritical carbon dioxide extracts of $C$. longa also were shown to have antioxidant activity in vitro and to inhibit carrageenan-induced inflammation in the rat paw [33]. However, the influence of a mixture of a hot water extract and a supercritical carbon dioxide extract of C. longa on chronic inflammation and general health conditions in humans is not clearly understood.

To evaluate the effect of a mixture of both C. longa extracts on chronic inflammation and associated health conditions, we measured blood levels of inflammatory markers and assessed general health with two questionnaires, the Medical Outcomes Study (MOS) 36-Item Short-Form Health Survey (SF-36) and the Profile of Mood States (POMS) scale, in middle-aged and elderly participants with overweight.

\section{Materials and methods Study design}

This was a 12-week, randomized, double-blind, placebocontrolled interventional study. All procedures involving human participants were approved by the institutional review board of Chiyoda Paramedical Care Clinic (Tokyo, Japan), and the study was conducted according to the Declaration of Helsinki. Before enrollment in the study, written informed consent was obtained from all participants. This study was performed by a contract research organization (CRO; CPCC Co., Ltd., Tokyo, Japan) at the 
Chiyoda Paramedical Care Clinic from June to December 2019 and was registered with the University hospital Medical Information Network (UMIN; Registration number, UMIN000037370). Figure 1 shows the Consolidated Standards of Reporting Trials (CONSORT) 2010 diagram of the flow of participants from enrollment to analysis [34]; the completed CONSORT checklist is provided in Table S1.

\section{Enrollment of participants}

Participants were recruited from July to September 2019. A total of 339 potential participants among people attending the Chiyoda Paramedical Care Clinic were consecutively assessed for eligibility. The inclusion criteria were age 50 to 69 years, overweight (body mass index [BMI] $\geq 23$ to $<30 \mathrm{~kg} / \mathrm{m}^{2}$ ) [35], blood glucose below $126 \mathrm{mg} / \mathrm{dL}$, and blood high-density cholesterol greater than or equal to $35 \mathrm{mg} / \mathrm{dL}$; both men and menopausal women were included. The exclusion criteria were as follows: (1) positive test for hepatitis $\mathrm{C}$ virus antibody or hepatitis B surface antigen, (2) use of medications or health foods that could possibly influence the results of this study, (3) history of heart, liver, kidney, or gastrointestinal disease, (4) history of circulatory disease, (5) excessive alcohol intake (mean daily consumption of $60 \mathrm{~g}$ or more), (6) excessive smoking (mean daily consumption of two packs or more), (7) extremely irregular dietary habits, (8) allergies to medications or foods (especially soybeans and gelatin), (9) participation in another trial, either currently or in the past 4 weeks, or plan to participate in another trial during the scheduled study period, (10) donation of blood within 1 month before the study, (11) males who have made a blood donation of $400 \mathrm{~mL}$ of blood within 3 months before the study, (12) females who made a blood donation of $400 \mathrm{~mL}$ within 4 months before the study, (13) males who have made a blood donation over an amount $(1200 \mathrm{~mL}$ minus the estimated volume of blood collected during the study within 1 year before the study, (14) females who have made a blood donation over an amount $(800 \mathrm{~mL}$ minus the estimated volume of blood collected during the study) within 1 year before the study, (15) judged to be unsuitable for the study for other reasons by the investigators.

\section{Study agent}

The composition of the capsules used in this study is described in Table 1. The base capsules were composed of gelatin, glycerin, soybean-derived emulsifier, and beeswax. Placebo capsules also contained carob and tartrazine as coloring agents so that they matched the color of the turmeric capsules, and turmeric capsules contained a mixture of a hot water and a supercritical carbon dioxide extract of C. longa (CLE, Turmeric Extract Mixture, House Wellness Foods). The extracts of C. longa were prepared according to the method described previously [36-38]. In brief, to obtain the hot water extract of $C$.

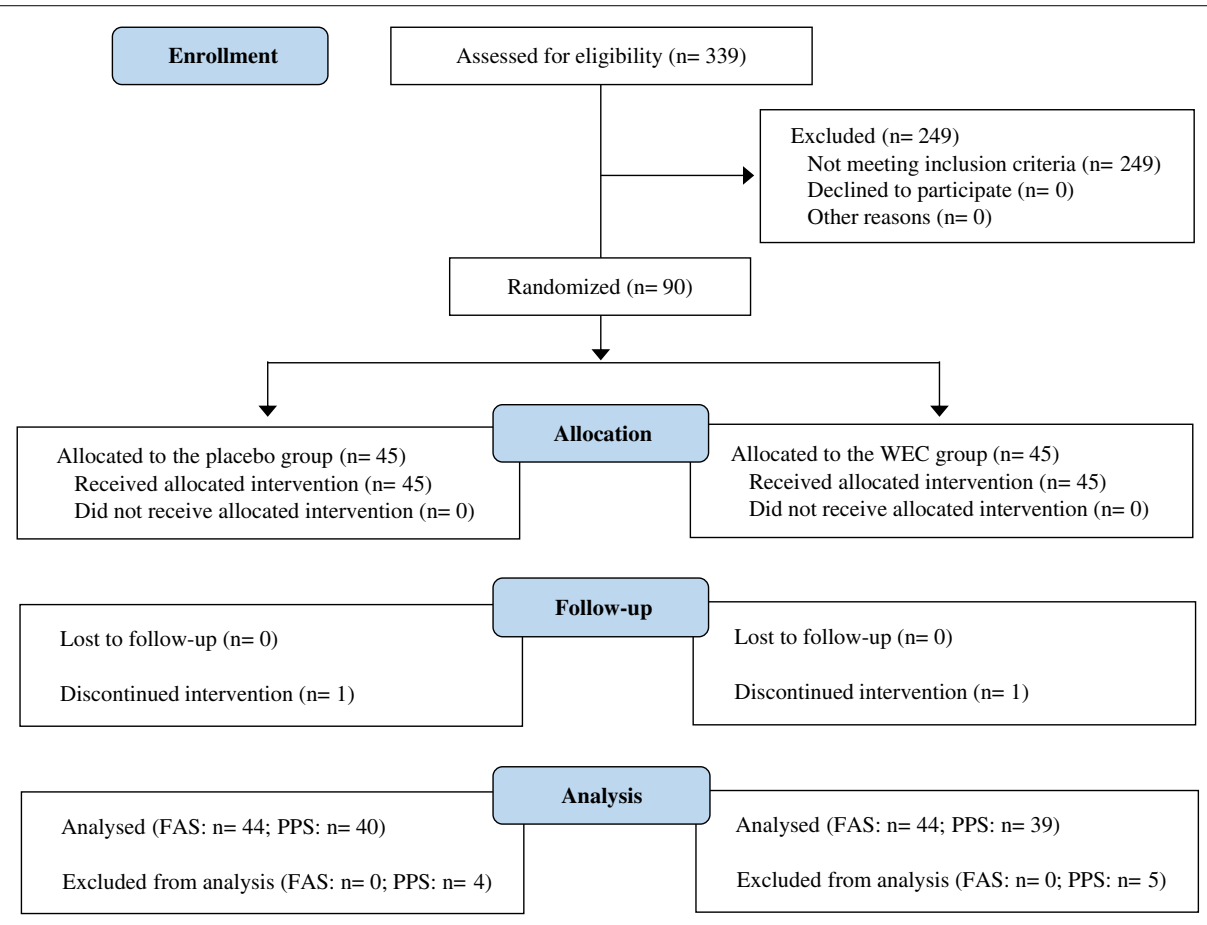

Fig. 1 Study flow diagram (CONSORT 2010) 
Table 1 Composition of the study capsules

\begin{tabular}{lll}
\hline & $\begin{array}{l}\text { Placebo } \\
\mathbf{( 0 . 9 7} \mathbf{g} / \mathbf{2} \text { capsules) }\end{array}$ & $\begin{array}{l}\text { CLE } \\
\mathbf{( 0 . 9 7 ~} \mathbf{g} / \mathbf{2} \\
\text { capsules) }\end{array}$ \\
\hline Energy, Kcal & 6.1 & 5.5 \\
Carbohydrate, g & 0.24 & 0.23 \\
Protein, g & 0.20 & 0.29 \\
Lipid, g & 0.47 & 0.38 \\
Sodium chloride, mg & 0.66 & 0.13 \\
Bisacurone, $\mu \mathrm{g}$ & 0 & 400 \\
Turmeronol A, $\mu \mathrm{g}$ & 0 & 100 \\
Turmeronol B, $\mu \mathrm{g}$ & 0 & 100 \\
\hline
\end{tabular}

CLE: a mixture of a hot water extract and a supercritical carbon dioxide extract of Curcuma longa

longa powder, the rhizomes of $C$. longa were extracted for $1 \mathrm{~h}$ with hot water at $98^{\circ} \mathrm{C}$, after which the supernatant was concentrated, mixed with dextrin, and spray dried. To obtain a supercritical carbon dioxide extract of $C$. longa oil, the rhizomes of $C$. longa were extracted for $6 \mathrm{~h}$ with carbon dioxide at $65^{\circ} \mathrm{C}$ and $150 \mathrm{bar}$, after which the supernatant was concentrated, mixed with vegetable oil, and filtered through a membrane filter $(1-\mu \mathrm{m}$ pore size).

\section{Intervention}

The intervention was conducted from September to December 2019. From the 339 potential participants, the CRO selected 90 participants who satisfied the inclusion and exclusion criteria, had no symptoms associated with acute inflammation, as assessed by their physicians. The test capsules and selected participants were randomly assigned numbers by the authors and the CRO, respectively, and the randomization list was stored carefully until the database was locked. Throughout the study, all participants and investigators were blinded to the treatment group. The participants were randomly allocated to the two groups by stratified randomization on the basis of sex, age, BMI, and CRP level. Each participant took two capsules containing CLE (CLE group, $n=45$ ) or two placebo capsules (placebo group, $\mathrm{n}=45$ ) once daily for 12 weeks. Participants visited the study center in weeks $0,4,8$, and 12 to undergo an interview by an experienced physician, physical measurements and tests, hematology and biochemistry tests, and urinalysis and to complete the questionnaires; adverse events were assessed at each visit. Hematology and biochemistry tests and urinalysis were performed by a contract laboratory company (LSI Medience Co., Ltd., Tokyo, Japan), and the questionnaires were evaluated by the CRO. The participants were asked to record the following information on a daily basis for the duration of the study: occurrence of diseases and symptoms; intake of study capsules, health foods, and medications; and reasons for taking medications, dosages, and duration of use. They were also asked to adhere to the following rules until the end of the study: (1) maintain their usual lifestyle through the study period, including diet, exercise, drinking, smoking, and medication; (2) avoid consuming health foods other than the study capsules; (3) avoid donating blood; and (4) avoid excessive drinking, smoking, exercise, fasting, and consumption of an unbalanced diet. Participants were instructed to fast, except for drinking water, after 9:00 pm on the day before each examination.

\section{Measurement of body weight and BMI}

Body weight was measured using a calibrated digital scale. BMI was calculated as body weight in kilograms divided by height in meters squared $\left(\mathrm{kg} / \mathrm{m}^{2}\right)$.

\section{Measurement of inflammatory markers}

The serum level of high-sensitivity CRP (hsCRP) was measured by an immunonephelometric method with an upper detection limit of $0.500 \mathrm{mg} / \mathrm{dL}$. For samples exceeding this limit, a remeasurement was performed by standard latex agglutination turbidimetry. The serum levels of C3 and C4 were determined by turbidimetric immunoassays, and plasma fibrinogen levels were measured with a thrombin method.

\section{The medical outcomes study 36-item short-form health survey}

The second edition of the MOS 36-Item Short-Form Health Survey (SF-36) is a widely used self-reported questionnaire that evaluates health-related QOL and has demonstrated good reliability and validity [39, 40]. Items are aggregated into the following eight subscales: physical functioning (PF), role physical (RP), bodily pain $(\mathrm{BP})$, general health $(\mathrm{GH})$, vitality $(\mathrm{VT})$, social functioning $(\mathrm{SF})$, role emotional (RE), and mental health $(\mathrm{MH})$. In our study, all items were transformed and summed according to the official manual to give scores from 0 to 100 points for each subscale, with higher scores indicating better QOL. The scores for the eight subscales were then used to obtain scores for the two main components, ie, the physical component summary (PCS) score and the mental component summary (MCS) score. Three subscales (PF, RP, and BP) are the main determinants of the PCS; three others (SF, RE, and $\mathrm{MH}$ ) are the main determinants of the MCS. The remaining two scales $(\mathrm{GH}$ and VT) were included in the calculation of both component summary scores. Then, the sums of the PCS and MCS were each multiplied by 10 , and 50 was added to achieve linear transformation to the T-score metric, which has a 
mean of 50 and a standard deviation of 10 in the general Japanese population.

\section{Profile of mood states scale}

The second edition of the Profile of Mood States (POMS) scale short version is a widely used self-reported questionnaire for rapidly assessing mood states, including both transient, fluctuating feelings and enduring affect states [41, 42]. The POMS scale contains 35 questions that assess the following seven moods: anger-hostility $(\mathrm{AH})$, confusion-bewilderment $(\mathrm{CB})$, depression-dejection (DD), fatigue-inertia (FI), tension-anxiety (TA), vigor-activity (VA), and friendliness (F). Participants were asked to indicate their mood states during the previous week on a 5-point scale ranging from "not-at-all" to "extremely" Total mood disturbance (TMD) scores were calculated for each subscale by the following formula: $\mathrm{TMD}=\mathrm{AH}+\mathrm{CB}+\mathrm{DD}+\mathrm{FI}+\mathrm{TA}-\mathrm{VA}$. High scores for $\mathrm{VA}$ and $\mathrm{F}$ indicate a positive mood state, whereas high scores for AH, CB, DD, FI, and TA and a high TMD indicate a negative mood state.

\section{Sample size}

To calculate the minimum number of participants required for adequate statistical power, we used the $G$ Power 3.1.9 program (University of Dusseldorf, Germany). In a previous clinical study, a green tea extract with anti-inflammatory activity reduced the serum CRP level by about $30 \%$ from baseline [43]. Therefore, a sample size of 45 participants per group was estimated to be sufficient for the present study on the basis of the following assumptions: $30 \%$ reduction of serum CRP by CLE, Cohen's d value $=0.60$, statistical power $=80 \%$, and type I error $=5 \%$ (two-tailed).

\section{Statistical analysis}

Statistical analysis was performed in the intention-totreat (ITT) population, which was defined as all randomized participants. The full analysis set (FAS) was used to assess safety, and the per-protocol set (PPS) was used to evaluate efficacy. In the efficacy assessment of inflammatory markers, we excluded the data of participants who were suspected to have acute inflammation because of a markedly increasing CRP or fibrinogen value or symptoms associated with acute inflammation, as diagnosed by a physician (common cold symptoms, acute lower back pain, physical injury, or proteinuria). All statistical analyses were performed with the IBM SPSS statistical software package (version 26) for Windows (IBM Corp., New York, USA). Results are presented as the mean (standard deviation [SD]). Baseline characteristics were compared between the two groups by the two-tailed unpaired Student's $t$ test when variance was homogeneous or the Aspin-Welch $t$ test when variance was heterogeneous, except for the results of sex and urinalysis, which were analyzed by the two-tailed Mann Whitney $U$ test. Changes from baseline were analyzed by repeated measures two-way analysis of variance (ANOVA; two groups $\times$ three time points) with the SPSS general linear model for determining the main effects of group and time and their interaction, followed by comparison between the placebo and CLE groups at each time point with the two-tailed unpaired Student's $t$ test when variance was homogeneous or the Aspin-Welch $t$ test when variance was heterogeneous. A probability (p) value less than 0.05 was considered to indicate statistical significance.

\section{Results}

\section{Participants}

The flow of participants through the trial is shown in Fig. 1. A total of 90 out of 339 potential participants were randomly allocated to the CLE group or the placebo group ( $n=45$ per group). Two participants dropped out before completing the study: One was in the placebo group and discontinued the study because of a marked reduction of body weight over the course of the study, and one was in the CLE group and declined to continue to participate because of a bone fracture resulting from a slip-and-fall accident while walking. Nine participants were excluded from the efficacy assessment (PPS analysis) because they did not comply with the protocol for the following reasons: change of dietary habits $(n=4$ in the CLE group and $n=4$ in the placebo group), and bone fracture resulting from a slip-and-fall accident while cycling ( $n=1$ in the CLE group). The other 79 participants completed the study. Baseline characteristics showed no significant differences between the CLE and placebo groups, except for a significantly higher serum $\mathrm{C} 4$ and glucose levels in the placebo group than in the CLE group (Tables 2 and 3). Both groups met the requirements for the mean $[\mathrm{SD}]$ intake of capsules (CLE group, $100.0 \%$ [0.2\%]; placebo group, 99.8\% [0.6\%]). Exercise was performed during the study by 11 participants in the CLE group and 12 in the placebo group and was not performed 28 participants in each group; the number of participants who exercised was not significantly different between the two groups $(p=0.862)$. In addition, among the participants who exercised, the mean [SD] number of days of exercise was not significantly different between the two groups (CLE group, 4.3 [9.1] days; placebo group, 4.0 [8.6] days; $p=0.868$ ).

\section{Effect of CLE on body weight and BMI}

The change of body weight from baseline was significantly lower in the CLE group than in the placebo 
Table 2 Baseline characteristics of the participants ${ }^{a}$

\begin{tabular}{|c|c|c|c|c|c|}
\hline & \multicolumn{2}{|c|}{$\begin{array}{l}\text { Placebo group } \\
(n=40)\end{array}$} & \multicolumn{2}{|c|}{$\begin{array}{l}\text { CLE group } \\
(n=39)\end{array}$} & \multirow[t]{2}{*}{$p$ value } \\
\hline & Mean & SD & Mean & SD & \\
\hline Sex, male/female, $n$ & $16 / 24$ & & $15 / 24$ & & 0.889 \\
\hline Age, years & 56.6 & 4.3 & 56.7 & 5.0 & 0.930 \\
\hline \multicolumn{6}{|c|}{ Physical measurements and tests } \\
\hline Height, cm & 162.5 & 8.5 & 162.5 & 8.5 & 0.985 \\
\hline Body weight, kg & 69.9 & 8.0 & 70.3 & 7.8 & 0.821 \\
\hline $\mathrm{BMI}, \mathrm{kg} / \mathrm{m}^{2}$ & 26.4 & 1.8 & 26.6 & 1.5 & 0.664 \\
\hline $\mathrm{SBP}, \mathrm{mmHg}$ & 122.9 & 12.8 & 119.7 & 14.7 & 0.308 \\
\hline $\mathrm{DBP}, \mathrm{mmHg}$ & 77.6 & 10.2 & 77.6 & 9.6 & 0.995 \\
\hline \multicolumn{6}{|l|}{ Serum inflammatory markers } \\
\hline $\mathrm{CRP}, \mathrm{mg} / \mathrm{dL}$ & 0.076 & 0.047 & 0.075 & 0.064 & 0.940 \\
\hline $\mathrm{C} 3, \mathrm{mg} / \mathrm{dL}$ & 110.8 & 12.6 & 104.7 & 14.2 & 0.073 \\
\hline $\mathrm{C} 4, \mathrm{mg} / \mathrm{dL}$ & 27.5 & 7.0 & 24.0 & 6.0 & 0.037 \\
\hline Fibrinogen, mg/dL & 285.7 & 43.8 & 288.5 & 45.0 & 0.797 \\
\hline \multicolumn{6}{|l|}{ Metabolic markers } \\
\hline Glucose, mg/dL & 92.3 & 8.7 & 88.5 & 6.4 & 0.031 \\
\hline $\mathrm{HbA} 1 \mathrm{c}, \%$ & 5.63 & 0.20 & 5.55 & 0.26 & 0.147 \\
\hline Triglyceride, mg/dL & 120.8 & 52.9 & 122.2 & 67.0 & 0.915 \\
\hline Total cholesterol, mg/dL & 231.4 & 36.8 & 221.2 & 37.5 & 0.226 \\
\hline LDL-cholesterol, mg/dL & 148.7 & 31.9 & 138.2 & 31.9 & 0.151 \\
\hline HDL-cholesterol, mg/dL & 58.2 & 11.9 & 58.2 & 16.6 & 0.980 \\
\hline
\end{tabular}

$B M I$ body mass index, CLE a mixture of a hot water extract and a supercritical carbon dioxide extract of Curcuma longa, DBP diastolic blood pressure, $\mathrm{HbA1C}$ hemoglobin A1c, HDL high-density lipoprotein, CRP C-reactive protein, C3 complement component 3, C4 complement component 4, LDL low-density lipoprotein

${ }^{\text {a }}$ Values represent the means and standard deviations for $n=40$ (placebo group) or $n=39$ (CLE group). Comparison of sex was performed with the two-tailed Mann Whitney $U$ test. Comparisons of physical measurements and tests, serum inflammatory markers, and metabolic markers were performed with the twotailed unpaired Student's $t$ test when variance was homogeneous or the AspinWelch $t$ test when variance was heterogeneous

group throughout the whole study period ( $p=0.009$ by repeated measures two-way ANOVA [r-ANOVA]) and they were significantly lower in weeks 4,8 , and 12 in the CLE group compared with the placebo group (Table 4) Similarly, the change of BMI from baseline was significantly lower in the CLE group than in the placebo group throughout the whole study period ( $p=0.007$ by r-ANOVA) and they were significantly lower in weeks 4 , 8 , and 12 in the CLE group compared with the placebo group (Table 4).

\section{Effect of CLE on inflammatory markers}

The change of CRP from baseline was tended to be lower in the CLE group than in the placebo group throughout the whole study period $(p=0.057$ by r-ANOVA) and it was tended to be lower in week 8 $(p=0.073)$ and significantly lower in week $12(p<0.05)$
Table 3 Baseline scores for the MOS 36-Item Short-Form Health Survey (SF-36) and Profile of Mood States (POMS) questionnaire ${ }^{a}$

\begin{tabular}{|c|c|c|c|c|c|}
\hline & \multicolumn{2}{|c|}{$\begin{array}{l}\text { Placebo } \\
\text { group } \\
(n=40)\end{array}$} & \multicolumn{2}{|c|}{$\begin{array}{l}\text { CLE group } \\
(n=39)\end{array}$} & \multirow[t]{2}{*}{$p$ value } \\
\hline & Mean & SD & Mean & SD & \\
\hline \multicolumn{6}{|l|}{ SF-36 scores, points } \\
\hline Physical functioning (PF) & 92.5 & 6.8 & 91.8 & 12.8 & 0.762 \\
\hline Role physical (RP) & 94.7 & 10.2 & 93.1 & 13.4 & 0.558 \\
\hline Bodily pain (BP) & 88.3 & 13.5 & 89.0 & 16.6 & 0.826 \\
\hline General health (GH) & 71.7 & 13.9 & 77.6 & 13.9 & 0.060 \\
\hline Vitality (VT) & 65.3 & 16.1 & 69.9 & 20.4 & 0.269 \\
\hline Social functioning (SF) & 94.7 & 10.2 & 91.7 & 14.4 & 0.287 \\
\hline Role emotional (RE) & 94.4 & 10.9 & 92.9 & 13.2 & 0.599 \\
\hline Mental health $(\mathrm{MH})$ & 80.1 & 12.2 & 79.4 & 15.4 & 0.812 \\
\hline $\begin{array}{l}\text { Physical component summary } \\
\text { (PCS) }\end{array}$ & 53.4 & 4.4 & 52.2 & 7.0 & 0.382 \\
\hline $\begin{array}{l}\text { Mental component summary } \\
\text { (MCS) }\end{array}$ & 56.5 & 5.9 & 58.0 & 8.8 & 0.358 \\
\hline \multicolumn{6}{|l|}{ POMS scores, points } \\
\hline Anger-hostility (AH) & 45.5 & 6.9 & 45.4 & 6.2 & 0.979 \\
\hline Confusion-bewilderment (CB) & 46.9 & 6.9 & 46.0 & 8.1 & 0.619 \\
\hline Depression-dejection (DD) & 47.3 & 6.8 & 47.0 & 7.5 & 0.877 \\
\hline Fatigue-inertia (FI) & 45.2 & 5.8 & 44.2 & 8.1 & 0.540 \\
\hline Tension-anxiety (TA) & 48.7 & 8.9 & 45.9 & 7.8 & 0.142 \\
\hline Vigor-activity (VA) & 54.4 & 9.1 & 56.3 & 9.2 & 0.362 \\
\hline Friendliness (F) & 56.3 & 9.4 & 56.5 & 9.3 & 0.901 \\
\hline Total mood disturbance (TMD) & 45.3 & 6.8 & 43.7 & 8.0 & 0.332 \\
\hline
\end{tabular}

CLE: a mixture of a hot water extract and a supercritical carbon dioxide extract of Curcuma longa

${ }^{a}$ Values represent the means and standard deviations for $n=40$ (placebo group) or $n=39$ (CLE group). Comparisons of SF-36 and POMS data were performed with the two-tailed unpaired Student's $t$ test when variance was homogeneous or the Aspin-Welch $t$ test when variance was heterogeneous

in the CLE group compared with the placebo group (Table 5). The changes of $\mathrm{C} 3$ from baseline showed no significant differences between the two groups throughout the whole study period (r-ANOVA), but it was significantly lower in week 12 in the CLE group than in the placebo group (Table 5). The changes of $\mathrm{C} 4$ and fibrinogen did not show significant differences between the two groups.

\section{Effect of CLE on SF-36 scores}

The changes of $\mathrm{MH}$ scores from baseline were significantly higher in the CLE group than in the placebo group over the whole study period ( $p=0.032, \mathrm{r}$-ANOVA) and it was significantly higher in week 8 in the CLE group compared with the placebo group (Table 6). The scores for the remaining seven SF-36 subscales did not show significant differences between the two groups. 
Table 4 Effect of Curcuma longa extract (CLE) on body weight and body mass index ${ }^{a}$

\begin{tabular}{|c|c|c|c|c|c|c|c|c|c|}
\hline & \multicolumn{6}{|c|}{ Change from baseline } & \multicolumn{3}{|c|}{ Repeated measures 2-way ANOVA } \\
\hline & \multicolumn{2}{|l|}{ Week 4} & \multicolumn{2}{|l|}{ Week 8} & \multicolumn{2}{|c|}{ Week 12} & \multirow[t]{2}{*}{ Group } & \multirow[t]{2}{*}{ Time } & \multirow[t]{2}{*}{ Interaction } \\
\hline & Mean & SD & Mean & SD & Mean & SD & & & \\
\hline \multicolumn{10}{|c|}{ Body weight, kg } \\
\hline Placebo & 0.31 & 0.72 & 0.52 & 0.93 & 0.65 & 0.86 & 0.009 & 0.037 & 0.583 \\
\hline CLE & $-0.18^{*}$ & 1.08 & $-0.04^{*}$ & 1.18 & $-0.03^{*}$ & 1.49 & & & \\
\hline \multicolumn{10}{|l|}{$\mathrm{BMI}, \mathrm{kg} / \mathrm{m}^{2}$} \\
\hline Placebo & 0.12 & 0.28 & 0.20 & 0.38 & 0.26 & 0.33 & 0.007 & 0.023 & 0.520 \\
\hline CLE & $-0.08^{*}$ & 0.41 & $-0.02^{*}$ & 0.46 & $-0.02^{*}$ & 0.57 & & & \\
\hline
\end{tabular}

$B M I$ body mass index

${ }^{a}$ Values represent the means and standard deviations for $n=40$ (placebo group) or $n=39$ (CLE group). * $p<0.05$ : Significant difference from the placebo group assessed by repeated measures two-way ANOVA, followed by the two-tailed unpaired Student's $t$ test when variance was homogeneous or the Aspin-Welch $t$ test when variance was heterogeneous

Table 5 Effect of Curcuma longa extract (CLE) on serum inflammatory markers ${ }^{\mathrm{a}}$

\begin{tabular}{|c|c|c|c|c|c|c|c|c|c|}
\hline & \multicolumn{6}{|c|}{ Change from baseline } & \multicolumn{3}{|c|}{ Repeated measures two-way ANOVA } \\
\hline & \multicolumn{2}{|c|}{ Week 4} & \multicolumn{2}{|c|}{ Week 8} & \multicolumn{2}{|l|}{ Week 12} & \multirow[t]{2}{*}{ Group } & \multirow[t]{2}{*}{ Time } & \multirow[t]{2}{*}{ Interaction } \\
\hline & Mean & SD & Mean & SD & Mean & SD & & & \\
\hline \multicolumn{10}{|l|}{$\mathrm{CRP}, \mathrm{mg} / \mathrm{dL}$} \\
\hline Placebo & 0.019 & 0.044 & 0.036 & 0.091 & 0.016 & 0.047 & 0.057 & 0.363 & 0.302 \\
\hline CLE & 0.021 & 0.089 & 0.002 & 0.032 & $-0.007^{*}$ & 0.035 & & & \\
\hline \multicolumn{10}{|l|}{$\mathrm{C} 3, \mathrm{mg} / \mathrm{dL}$} \\
\hline Placebo & 4.13 & 7.94 & 0.10 & 9.33 & 7.26 & 9.00 & 0.514 & $<0.001$ & 0.138 \\
\hline CLE & 4.00 & 8.14 & 1.41 & 11.90 & $2.66^{*}$ & 8.20 & & & \\
\hline \multicolumn{10}{|l|}{$\mathrm{C} 4, \mathrm{mg} / \mathrm{dL}$} \\
\hline Placebo & 0.06 & 2.78 & 0.71 & 3.57 & 1.48 & 3.47 & 0.366 & 0.094 & 0.135 \\
\hline CLE & 0.28 & 2.58 & -0.07 & 3.42 & 0.34 & 2.69 & & & \\
\hline \multicolumn{10}{|c|}{ Fibrinogen, mg/dL } \\
\hline Placebo & 9.0 & 27.9 & 11.4 & 46.3 & 15.1 & 35.5 & 0.648 & 0.371 & 0.950 \\
\hline CLE & 5.3 & 50.6 & 3.7 & 29.7 & 12.0 & 37.8 & & & \\
\hline
\end{tabular}

CRP: C-reactive protein; C3: complement component 3; C4: complement component 4

a Values represent the means and standard deviations at 4, 8, and 12 weeks for $n=31,31$, and 31 (placebo group) or $n=29,27$, and 29 (CLE group), respectively. ${ }^{*} p<0.05$ : Significant difference from the placebo group by repeated measures two-way ANOVA, followed by the two-tailed unpaired Student's $t$ test when variance was homogeneous or the Aspin-Welch $t$ test when variance was heterogeneous

\section{Effect of CLE on POMS scores}

The change of the AH score from baseline was significantly lower in CLE group than the placebo group throughout the study period ( $p=0.022, \mathrm{r}-\mathrm{ANOVA})$ and it was significantly lower in weeks 4 and 12 in the CLE group compared with the placebo group (Table 7). The other POMS scores did not show significant differences between the two groups.

\section{Safety of the intervention}

Adverse events were assessed in the ITT population (placebo group, $n=45$; CLE group, $n=45$ ). In the placebo group, the following adverse events occurred: headache (three cases), headache and abdominal pain (one case), headache and mood disturbance (one case), pharyngeal pain (one case), chest pain (one case), abdominal pain (one case), common cold symptoms (seven cases), diarrhea (three cases), stomach upset (two cases), dental decay (two cases), fatigue (one case), insect bite (one case), hives (one case), foot blister (one case), scratch (one case), abdominal fullness (one case), positive urinary blood (one case), increased CRP (four cases), increased $\gamma$-glutamyl transferase (two cases), increased creatinine phosphokinase (two cases), increased aspartate aminotransferase (two cases), increased body weight (two cases), and decreased body weight (one case); and in 
Table 6 Effect of Curcuma longa extract (CLE) on the MOS 36-Item Short-Form Health Survey (SF-36) scores ${ }^{a}$

\begin{tabular}{|c|c|c|c|c|c|c|c|c|c|}
\hline & \multicolumn{6}{|c|}{ Change from baseline } & \multicolumn{3}{|c|}{ Repeated measures two-way ANOVA } \\
\hline & \multicolumn{2}{|c|}{ Week 4} & \multicolumn{2}{|c|}{ Week 8} & \multicolumn{2}{|c|}{ Week 12} & \multirow[t]{2}{*}{ Group } & \multirow[t]{2}{*}{ Time } & \multirow[t]{2}{*}{ Interaction } \\
\hline & Mean & SD & Mean & SD & Mean & SD & & & \\
\hline \multicolumn{10}{|c|}{ Physical functioning (PF) } \\
\hline Placebo & 1.00 & 7.18 & 0.38 & 7.20 & 0.25 & 6.20 & 0.768 & 0.081 & 0.343 \\
\hline CLE & 0.77 & 5.91 & 1.71 & 5.61 & 0.64 & 7.18 & & & \\
\hline \multicolumn{10}{|c|}{ Role physical (RP) } \\
\hline Placebo & 1.25 & 10.60 & 0.78 & 12.10 & 1.87 & 8.27 & 0.719 & 0.158 & 0.538 \\
\hline CLE & -0.65 & 12.40 & 0.16 & 9.36 & 2.24 & 10.08 & & & \\
\hline \multicolumn{10}{|c|}{ Bodily pain (BP) } \\
\hline Placebo & -0.8 & 14.0 & -2.0 & 14.3 & -2.1 & 11.4 & 0.544 & 0.612 & 0.999 \\
\hline CLE & -2.4 & 14.9 & -3.1 & 13.9 & -3.7 & 15.6 & & & \\
\hline \multicolumn{10}{|c|}{ General health (GH) } \\
\hline Placebo & -0.30 & 10.99 & 0.18 & 13.35 & 0.63 & 11.71 & 0.121 & 0.881 & 0.884 \\
\hline CLE & -3.08 & 9.73 & -3.58 & 10.91 & -3.05 & 12.80 & & & \\
\hline \multicolumn{10}{|l|}{ Vitality (VT) } \\
\hline Placebo & -2.51 & 14.36 & -0.94 & 11.88 & 1.71 & 10.49 & 0.692 & 0.040 & 0.734 \\
\hline CLE & -2.56 & 13.28 & -1.32 & 11.99 & -0.32 & 11.99 & & & \\
\hline \multicolumn{10}{|c|}{ Social functioning (SF) } \\
\hline Placebo & -0.94 & 13.69 & 0.31 & 14.57 & -0.63 & 13.56 & 0.438 & 0.221 & 0.749 \\
\hline CLE & 0.32 & 18.02 & 3.95 & 14.85 & 1.92 & 12.35 & & & \\
\hline \multicolumn{10}{|c|}{ Role emotional (RE) } \\
\hline Placebo & 0.63 & 11.99 & 0.84 & 12.20 & 1.04 & 12.27 & 0.924 & 0.648 & 0.850 \\
\hline CLE & -0.21 & 13.04 & 0.88 & 11.76 & 1.49 & 11.78 & & & \\
\hline \multicolumn{10}{|c|}{ Mental health $(\mathrm{MH})$} \\
\hline Placebo & -3.63 & 10.50 & -3.38 & 11.29 & -1.75 & 9.37 & 0.032 & 0.127 & 0.416 \\
\hline CLE & -0.90 & 9.86 & $2.89^{*}$ & 10.24 & 1.92 & 10.68 & & & \\
\hline \multicolumn{10}{|c|}{ Physical component summary (PCS) } \\
\hline Placebo & 1.22 & 4.85 & 0.77 & 4.66 & 0.54 & 3.67 & 0.574 & 0.836 & 0.491 \\
\hline CLE & 0.23 & 4.97 & 0.28 & 4.02 & 0.52 & 4.63 & & & \\
\hline \multicolumn{10}{|c|}{ Mental component summary (MCS) } \\
\hline Placebo & -1.76 & 5.10 & -1.18 & 5.33 & -0.38 & 4.39 & 0.618 & 0.144 & 0.766 \\
\hline CLE & -1.21 & 5.72 & -0.10 & 4.55 & -0.37 & 5.24 & & & \\
\hline
\end{tabular}

${ }^{a}$ Values represent the means and standard deviations for $n=40$ (placebo group) or $n=39$ (CLE group). ${ }^{*} p<0.05$ : Significant difference from the placebo group by repeated measures two-way ANOVA, followed by the two-tailed unpaired Student's $t$ test when variance was homogeneous or the Aspin-Welch $t$ test when variance was heterogeneous

the CLE group, the following adverse events occurred: headache (one case), lower back pain (two cases), stomach pain (one case), knee pain (one case), arthritis pain (one case), calf cramp (one case), stiff joint (one case), common cold symptoms (eleven cases), cough (four cases), nasal discharge (two cases), bone fracture (two cases), fatigue (one case), uveitis (one case), insect bite (one case), scratch (one case), suppuration (one case), positive urinary protein (two cases), increased CRP (nine cases), increased creatinine phosphokinase (five cases), increased $\gamma$-glutamyl transferase (four cases), increased alanine aminotransferase (one case), increased total bilirubin (one case), increased body weight (one case), and decreased body weight (one case). These adverse events were mild, and an experienced physician judged that they were unrelated to the dietary intervention. Safety parameters (hematology and biochemistry tests, urinalysis, and physical measurements and tests) were assessed in the FAS population (placebo group, $n=44$; CLE group, $\mathrm{n}=44$ ) and did not differ significantly between the two groups, except for urinary protein, which increased in four participants in the placebo group but in no participants in the CLE group. Before the study, we conducted an open-label, one-arm safety study 
Table 7 Effect of Curcuma longa extract (CLE) on the Profile of Mood States (POMS) scores ${ }^{a}$

\begin{tabular}{|c|c|c|c|c|c|c|c|c|c|}
\hline & \multicolumn{6}{|c|}{ Change from baseline } & \multicolumn{3}{|c|}{ Repeated measures two-way ANOVA } \\
\hline & \multicolumn{2}{|l|}{ Week 4} & \multicolumn{2}{|c|}{ Week 8} & \multicolumn{2}{|c|}{ Week 12} & \multirow[t]{2}{*}{ Group } & \multirow[t]{2}{*}{ Time } & \multirow[t]{2}{*}{ Interaction } \\
\hline & Mean & SD & Mean & SD & Mean & SD & & & \\
\hline \multicolumn{10}{|c|}{ Anger-hostility (AH) } \\
\hline Placebo & 1.95 & 4.76 & 1.55 & 6.02 & 1.75 & 5.29 & 0.022 & 0.706 & 0.472 \\
\hline CLE & $-0.69^{*}$ & 5.37 & 0.16 & 6.01 & $-1.10^{*}$ & 5.40 & & & \\
\hline \multicolumn{10}{|c|}{ Confusion-bewilderment (CB) } \\
\hline Placebo & -0.10 & 4.80 & 0.82 & 6.16 & 0.00 & 4.54 & 0.885 & 0.956 & 0.367 \\
\hline CLE & -0.64 & 4.37 & 0.71 & 5.93 & -0.97 & 4.49 & & & \\
\hline \multicolumn{10}{|c|}{ Depression-dejection (DD) } \\
\hline Placebo & 0.90 & 4.42 & 0.53 & 4.86 & 0.35 & 5.37 & 0.312 & 0.287 & 0.285 \\
\hline CLE & -0.64 & 4.37 & 0.71 & 5.93 & -0.97 & 4.49 & & & \\
\hline \multicolumn{10}{|c|}{ Fatigue-inertia (FI) } \\
\hline Placebo & -0.03 & 4.81 & -0.70 & 4.87 & -0.25 & \multirow{2}{*}{$\begin{array}{l}5.23 \\
6.82\end{array}$} & 0.900 & 0.433 & 0.294 \\
\hline CLE & -0.05 & 6.73 & 0.11 & 7.05 & -1.46 & & & & \\
\hline \multicolumn{10}{|c|}{ Tension-anxiety (TA) } \\
\hline Placebo & -1.70 & 7.77 & -2.58 & 6.00 & -1.48 & 6.99 & 0.331 & 0.469 & 0.108 \\
\hline CLE & 0.10 & 7.36 & -0.18 & 7.00 & -1.90 & 6.69 & & & \\
\hline \multicolumn{10}{|c|}{ Vigor-activity (VA) } \\
\hline Placebo & 1.58 & 7.19 & 1.08 & 8.23 & 2.10 & 8.74 & 0.141 & 0.184 & 0.841 \\
\hline CLE & -0.23 & 5.94 & -1.55 & 6.20 & 0.13 & 7.81 & & & \\
\hline \multicolumn{10}{|c|}{ Friendliness (F) } \\
\hline Placebo & 0.05 & 8.19 & -0.63 & 9.62 & -0.33 & 8.46 & 0.983 & 0.706 & 0.989 \\
\hline CLE & 0.00 & 7.19 & -0.45 & 7.83 & -0.15 & 8.79 & & & \\
\hline \multicolumn{10}{|c|}{ Total mood disturbance (TMD) } \\
\hline Placebo & -0.05 & 4.62 & -0.65 & 4.15 & -0.28 & 3.89 & 0.894 & 0.374 & 0.109 \\
\hline CLE & -0.23 & 5.04 & 0.68 & 6.54 & -1.08 & 5.48 & & & \\
\hline
\end{tabular}

a Values represent the means and standard deviations for $n=40$ (placebo group) or $n=39$ (CLE group). ${ }^{*} p<0.05$ : Significant difference from the placebo group by repeated measures two-way ANOVA, followed by the two-tailed unpaired Student's $t$ test when variance was homogeneous or the Aspin-Welch $t$ test when variance was heterogeneous

in which twenty participants (mean [SD] age 40.0 [13.1] years) consumed excess dose of CLE (10 capsules/day, ie, a 5-fold higher dose than in this study) for 4weeks; this open-label study found no adverse effects of the intervention on hematology or biochemistry tests, urinalysis, or physical measurements and tests (data not shown).

\section{Discussion}

This 12-week, randomized, double-blind, placebo-controlled study was performed to investigate the effect of a mixture of a hot water extract and a supercritical carbon dioxide extract of C. longa (CLE) on chronic inflammation and general health in middle-aged to elderly participants with overweight. We found that intake of CLE significantly improved body weight, BMI, and serum CRP and C3 levels. In addition, the CLE group had a significantly higher MH score on the SF-36 and a significantly lower AH score on the POMS. These results suggest that daily intake of CLE could potentially reduce chronic inflammation and improve mental health and negative mood states.

According to the World Health Organization, overweight and obesity are defined as an abnormal or excessive fat accumulation that presents a risk to health. BMI is the most commonly used indicator of overweight and obesity. BMI and associated factors show seasonal variation; for example, BMI, fat mass, and dietary fat intake were higher and levels of physical activity were lower in winter than in summer $[44,45]$. In the present study, we also demonstrated that body weight and BMI increased from baseline (summer) to week 12 (winter) (Table 4). High BMI values are risk factors for metabolic diseases, cardiovascular disease, Alzheimer disease, depression, and cancer [46]. In the present study, the CLE group showed a significantly lower in BMI from baseline at 4,8 , and 12 weeks compared with the placebo group (Table. 4), but the number of participants who reported exercising was not different 
between the CLE and placebo groups. Animals studies also showed that dietary intake of C. longa extract significantly inhibited body weight gain and visceral fat accumulation in high fat diet-induced obese rats $[47,48]$. Therefore, CLE may inhibit the accumulation of visceral fat, resulting in improved BMI values. However, future research will need to clarify the effect of CLE on visceral fat volume in humans with computed tomographic scan analysis [49] or abdominal bioelectrical impedance analysis [50].

Acute phase proteins such as CRP and C3 are generally used as systemic inflammatory markers [14, 20]. These proteins have also been reported to show seasonal variation, with higher values in winter than in summer [51-53]. In the present study, we also observed that serum CRP and C3 levels were higher at baseline (summer) than at week 12 (winter) (Table 5). Slight elevations of CRP accurately detected by hsCRP assay are now considered as a marker of low-grade inflammation [3, 4]. Slightly elevated hsCRP $(0.07-0.11 \mathrm{mg} / \mathrm{dL})$ was reported to be associated with an increased risk of metabolic syndrome [7], cardiovascular disease [8], coronary heart disease [54], myocardial infarction [55], diabetes [56], and colon cancer [11]. Increases in serum C3 have been related to the development of diseases associated with low-grade inflammation [20], and the disease risks may be reduced by anti-inflammatory agents [57-59]. In the present study in middle-aged and elderly participants with overweight, CLE significantly improved the serum levels of CRP and C3 (Table 5). These results suggest that CLE may reduce the systemic low-grade inflammation associated with aging and obesity and thus may be able to decrease the risk of chronic inflammatory diseases in these populations.

Low-grade inflammation is induced by several factors, including excessive intake of nutrients (fatty acids and glucose) [6], endoplasmic reticulum stress [3], and damage-associated molecular patterns [4]. These triggers have been reported to promote the expression of proinflammatory cytokines that induce the production of inflammatory markers, including CRP, complement proteins, and fibrinogen $[3,4,6]$. In the present study, CLE significantly improved CRP and C3 levels but not $\mathrm{C} 4$ and fibrinogen levels (Table 5). Activation of transcription factor nuclear factor kappa B (NF-kB) has been known to increase hepatic production of CRP and C3 [14], but the genes of $\mathrm{C} 4$ and fibrinogen have no NF-kB binding sites near the promotor region [60-63]. In fact, activators of NF-kB, such as tumor necrosis factor- $\alpha$ (TNF- $\alpha$ ) and interleukin-1 $\beta$ (IL-1 $\beta$ ), were reported to be unable to induce the production of $\mathrm{C} 4$ and fibrinogen [64-66]. A hot water extract of $C$. longa was reported to inhibit TNF- $\alpha$-induced phosphorylation of I kappa B-alpha
(IkB $\alpha)$, which can lead to activation of NF-kB [37]. Furthermore, turmeronol $\mathrm{A}$ and turmeronol $\mathrm{B}$ isolated from C. longa were shown to inhibit lipopolysaccharideinduced NF-kB activation in macrophages [67]. Taken together, these findings suggest that CLE may reduce $\mathrm{CRP}$ and $\mathrm{C} 3$ but not $\mathrm{C} 4$ and fibrinogen through inhibition of the NF-kB pathway.

QOL is defined as an individual's perception of their position in life embedded in a cultural, social, and environmental context [68]. Health-related QOL (HR-QOL) can be evaluated by the self-reported SF-36 questionnaire, which measures physical and mental health. In the present study, CLE significantly improved the SF-36 subscale score for mental health $(\mathrm{MH})$ (Table 6). Chronic lowgrade inflammation may be related to impaired HR-QOL [69]: Inflammation is known to reduce cellular energy levels and to cause central nervous system inflammation, circadian dysfunction, and fatigue, which together can lead to mental health problems, such as depression, anxiety, and sleep disturbance [10, 70, 71]. Middle-aged participants with fatigue were reported to have increased plasma CRP levels [72]. A follow-up study showed that high levels of CRP predicted fatigue [73]. In addition, compared with participants without fatigue, participants with fatigue and low-grade inflammation as measured by CRP were shown to have mental health problems, including psychological distress, depression, and sleep problems [72]. Previously, etiological studies showed a negative association between serum CRP levels and the SF-36 MH score in patients with a neural injury, such as spinal cord injury [21]. Depressed participants were reported to have significantly higher serum C3 levels than healthy participants [74]. In previous clinical studies, daily intake of medicinal foods with anti-inflammatory activity improved the SF-36 $\mathrm{MH}$ score in healthy individuals with normal weight and overweight $[75,76]$. Therefore, CLE may improve mental health by alleviating undesirable symptoms related to inflammation.

The POMS is a widely used self-reported questionnaire that measures negative and positive mood states, and it also has been used to evaluate mood disturbance [41]. In the present study, intake of CLE significantly improved negative mood, as indicated by improvement in the POMS AH score (Table 7). Negative mood states are known to be influenced by inflammation. Crosssectional studies found a significant positive correlation between anger and hostility and serum CRP levels [22]. A previous clinical study showed that a social stress task, the Trier Social Stress Test, not only increased systemic levels of CRP [77] and inflammatory cytokines, but also caused mood disturbance, including anger [78] and anxiety [79]. In a follow-up study, participants with psychological problems (anger and hostility) were 
shown to have higher levels of serum C3 than healthy participants [23]. Intervention studies demonstrated that daily intake of the medical herb Hochuekkito, which has anti-inflammatory activity [80], improves the AH POMS score in elderly subjects [81]. Therefore, in our study CLE may have improved the negative mood state of anger and hostility by reducing systemic lowgrade inflammation.

Mental health problems and mood disturbances are known to be associated with not only systemic inflammation $[79,82]$ but also neuroinflammation [83, 84]. Brain macrophages, also known as microglial cells, are central players in promoting the development of neuroinflammation by producing inflammatory cytokines that lead to the production of indoleamine 2, 3-dioxygenase (IDO) [83]. Induction of IDO expression promotes the metabolism of tryptophan into the neurotoxic metabolites of kynurenine and decreases the level of natural antidepressant compounds such as serotonin, which is derived from tryptophan [82]. Depression-like symptoms were shown to improve in animal models treated with IDO inhibitors [84]. In addition, a systematic review and meta-analysis of 18 clinical trials found an antidepressant effect for minocycline, a suppressor of microglial activation [85]. In activated microglial cells, C. longa extract, turmeronol A, and turmeronol B were found to inhibit the production of inflammatory mediators, including TNF- $\alpha$ and IL-6 [86, 87]. In addition, in animal studies $C$. longa extract inhibited the neuroinflammation associated with fatigue [88], depression [27], memory impairment [86], and anxiety- and sleep deprivation-induced behavior abnormalities [89, 90]. In the present study, dietary supplementation with CLE improved mental health and negative mood state, suggesting that these improvements could be related in part to inhibition of microglial activation in the central nervous system. Future studies need to investigate the effect of CLE on human microglial activation.

\section{Conclusion}

We conducted a 12-week, randomized, double-blind, placebo-controlled study in middle-aged and elderly participants with overweight. Compared with the placebo group, body weight, BMI, and serum levels of CRP and C3 were significantly lower in the CLE group. In addition, the CLE group showed a significant improvement in the SF-36 subscale score for mental health and the POMS score for anger and hostility. These results suggest that intake of a mixture of a hot water extract and supercritical carbon dioxide extract of C. longa may have the potential to improve mental health and negative mood state by reducing chronic low-grade inflammation.
Abbreviations

AH: Anger-hostility; ANOVA: Analysis of variance; BMI: Body mass index; CRP: C-reactive protein; CLE: A mixture of a hot water extract and a supercritical carbon dioxide extract of Curcuma longa; C3: Complement component 3; C4: Complement component 4; FAS: Full analysis set; hsCRP: High-sensitive C-reactive protein; HR-QOL: Health-related QOL; IL: Interleukin; ITT: Intensionto-treat; MH: Mental health; NF-kB: Nuclear factor kappa B; POMS: Profile of mode state; PPS: Per-protocol set; QOL: Quality of life; r-ANOVA: Repeated measures two-way ANOVA; MOS SF-36: Medical Outcomes Study 36-item short-form health survey; TNF-a: Tumor necrosis factor-alpha; UMIN: University hospital Medical Information Network.

\section{Supplementary Information}

The online version contains supplementary material available at https://doi. org/10.1186/s12937-021-00748-8.

Additional file 1: Table S1. CONSORT 2010 checklist of information to include when reporting a randomized trial*.

\section{Acknowledgments}

This research received no specific grant from any funding agency, or from the commercial or not-for-profit sectors. The authors thank Koichi Taoka, Naohiro Mukaida, Takahiro Kishi, and Shuya Taguchi from House Wellness Foods Corp. for support in planning the study schedule and preparing test capsules. The authors also thank Suguru Fujiwara, Makoto Ichinohe, Aiko Ishiguro, Dr. Toshiharu Namba, Makiko Uchida, and Toshiki Ando from CPCC Co., Ltd. for support with conducting the study and statistical analysis. In addition, the authors thank Jacquie Klesing (who was not involved in this study), Board-certified Editor in the Life Sciences (ELS) from Yamada Translation Bureau, Inc. for checking the English grammar of the manuscript.

\section{Authors' contributions}

The authors' contributions were as follows: Ryusei Uchio, Kengo Kawasaki, Koutarou Muroyama, Shinji Murosaki, Yoshihiro Yamamoto, and Yoshitaka Hirose designed the study; Ryusei Uchio, Kengo Kawasaki, and Shinji Murosaki conducted the study; Ryusei Uchio, Kengo Kawasaki, Chinatsu OkudaHanafusa, Ryosuke Saji, and Shinji Murosaki analyzed data; Ryusei Uchio, Kengo Kawasaki, Koutarou Muroyama, Shinji Murosaki, Yoshihiro Yamamoto, and Yoshitaka Hirose participated in interpretation of the results; Ryusei Uchio, Chinatsu Okuda-Hanafusa, Ryosuke Saji, and Shinji Murosaki wrote the manuscript; Yoshitaka Hirose had primary responsibility for the final content of the manuscript. All authors read and approved the final manuscript.

Authors' information

Not applicable.

Funding

This study received no external funding and was conducted by a CRO (CPCC Co., Ltd., Tokyo, Japan) with financial support from House Wellness Foods Corp.

Availability of data and materials

Not applicable.

\section{Declarations}

\section{Ethics approval and consent to participate}

The study was performed in accordance with the Declaration of Helsinki, was approved by the institutional review board of Chiyoda Paramedical Care Clinic, and registered with the UMIN (Registration number, UMIN000037370). A written informed consent was obtained from all participants.

\section{Consent for publication \\ Not applicable.}

\section{Competing interests}

All authors are employees of House Wellness Foods Corp., which markets health food products. 
Received: 6 December 2020 Accepted: 5 October 2021

Published online: 13 November 2021

\section{References}

1. Netea MG, Balkwill F, Chonchol M, Cominelli F, Donath MY, GiamarellosBourboulis EJ, et al. A guiding map for inflammation. Nat Immunol. 2017;18:826-31.

2. Furman D, Campisi J, Verdin E. Chronic inflammation in the etiology of disease across the life span. Nat Med. 2019;25:1822-32.

3. Kushner I, Samols D, Magrey M. A unifying biologic explanation for "highsensitivity" C-reactive protein and "low-grade" inflammation. Arthritis care \& research. 2010;62:442-6.

4. Leon-Pedroza Jl, Gonzalez-Tapia LA, del Olmo-Gil E, Castellanos-Rodriguez D, Escobedo G, Gonzalez-Chavez A. Low-grade systemic inflammation and the development of metabolic diseases: from the molecular evidence to the clinical practice. Cir Cir. 2015;83:543-51.

5. Calder PC, Bosco N, Bourdet-Sicard R, Capuron L, Delzenne N, Dore J, et al. Health relevance of the modification of low grade inflammation in ageing (inflammageing) and the role of nutrition. Ageing Res Rev. 2017:40:95-119.

6. Kolb H, Mandrup-Poulsen T. The global diabetes epidemic as a consequence of lifestyle-induced low-grade inflammation. Diabetologia. 2010;53:10-20.

7. Tamakoshi $\mathrm{K}$, Yatsuya $\mathrm{H}$, Kondo T, Hori Y, Ishikawa M, Zhang H, et al. The metabolic syndrome is associated with elevated circulating C-reactive protein in healthy reference range, a systemic low-grade inflammatory state. Int J Obes Relat Metab Disord. 2003;27:443-9.

8. Ridker PM. High-sensitivity C-reactive protein: potential adjunct for global risk assessment in the primary prevention of cardiovascular disease. Circulation. 2001;103:1813-8.

9. Tao Q, Ang TFA, DeCarli C, Auerbach SH, Devine S, Stein TD, et al. Association of Chronic low-grade Inflammation with Risk of Alzheimer disease in ApoE4 carriers. JAMA Netw Open. 2018;1:e183597.

10. Lasselin J, Capuron L. Chronic low-grade inflammation in metabolic disorders: relevance for behavioral symptoms. Neuroimmunomodulation. 2014;21:95-101.

11. Otani T, Iwasaki M, Sasazuki S, Inoue M, Tsugane S. Group JPHCBPS: plasma C-reactive protein and risk of colorectal cancer in a nested case-control study: Japan public health center-based prospective study. Cancer Epidemiology and Prevention Biomarkers. 2006;15:690-5.

12. Giovannini S, Onder G, Liperoti R, Russo A, Carter C, Capoluongo E, et al. Interleukin-6, C-reactive protein, and tumor necrosis factor-alpha as predictors of mortality in frail, community-living elderly individuals. J Am Geriatr Soc. 2011;59:1679-85.

13. Bonaccio M, Di Castelnuovo A, Pounis G, De Curtis A, Costanzo S, Persichillo $\mathrm{M}$, et al. A score of low-grade inflammation and risk of mortality: prospective findings from the Moli-sani study. Haematologica. 2016;101:1434-41.

14. Zhou Z, Xu MJ, Gao B. Hepatocytes: a key cell type for innate immunity. Cell Mol Immunol. 2016;13:301-15.

15. Rhodes B, Fürnrohr BG, Vyse TJ. C-reactive protein in rheumatology: biology and genetics. Nat Rev Rheumatol. 2011;7:282-9.

16. Devaraj S, Jialal I. C-reactive protein polarizes human macrophages to an $\mathrm{M} 1$ phenotype and inhibits transformation to the M2 phenotype. Arterioscler Thromb Vasc Biol. 2011;31:1397-402.

17. Devaraj S, Davis B, Simon SI, Jialal I. CRP promotes monocyte-endothelial cell adhesion via Fcgamma receptors in human aortic endothelial cells under static and shear flow conditions. Am J Physiol Heart Circ Physiol. 2006;291:H1170-6.

18. Markiewski MM, Lambris JD. The role of complement in inflammatory diseases from behind the scenes into the spotlight. Am J Pathol. 2007;171:715-27.

19. Davalos $D$, Akassoglou K. Fibrinogen as a key regulator of inflammation in disease. Semin Immunopathol. 2012;34:43-62.

20. Nadar SK, Lip GY. New insights into complement C3 and inflammation in hypertension. J Hum Hypertens. 2007;21:261-3.

21. Sabour H, Latifi S, Soltani Z, Shakeri H, Norouzi Javidan A, Ghodsi SM, et al. C-reactive protein as an available biomarker determining mental component of health-related quality of life among individuals with spinal cord injury. J Spinal Cord Med. 2017;40:329-37.

22. Suarez EC. C-reactive protein is associated with psychological risk factors of cardiovascular disease in apparently healthy adults. Psychosom Med. 2004:66:684-91.

23. Boyle SH, Jackson WG, Suarez EC. Hostility, anger, and depression predict increases in C3 over a 10-year period. Brain Behav Immun. 2007;21:816-23.

24. Amalraj A, Pius A, Gopi S, Gopi S. Biological activities of curcuminoids, other biomolecules from turmeric and their derivatives-a review. J Tradit Complement Med. 2017;7:205-33.

25. Aggarwal BB, Yuan W, Li S, Gupta SC. Curcumin-free turmeric exhibits anti-inflammatory and anticancer activities: identification of novel components of turmeric. Mol Nutr Food Res. 2013;57:1529-42.

26. Mehra KS, Mikuni I, Gupta U, Gode KD. Curcuma longa (Linn) drops in corneal wound healing. Tokai J Exp Clin Med. 1984;9:27-31.

27. Yu ZF, Kong LD, Chen Y. Antidepressant activity of aqueous extracts of Curcuma longa in mice. J Ethnopharmacol. 2002;83:161-5.

28. LiY, Shi X, Zhang J, Zhang X, Martin RC. Hepatic protection and anticancer activity of curcuma: a potential chemopreventive strategy against hepatocellular carcinoma. Int J Oncol. 2014;44:505-13.

29. Anandakumar S, Joseph JA, Bethapudi B, Agarwal A, Jung E-B. Antiinflammatory effects of turmeric (Curcuma longa L.) extract on acute and chronic inflammation models. Journal of the Korean Society of Food Science and Nutrition. 2014;43:612-7.

30. Sengupta M, Sharma GD, Chakraborty B. Hepatoprotective and immunomodulatory properties of aqueous extract of Curcuma longa in carbon tetra chloride intoxicated Swiss albino mice. Asian Pac J Trop Biomed. 2011;1:193-9.

31. Uchio R, Murosaki S, Ichikawa H. Hot water extract of turmeric (Curcuma longa) prevents non-alcoholic steatohepatitis in mice by inhibiting hepatic oxidative stress and inflammation. J Nutr Sci. 2018;7:e36.

32. Mun J, Kim S, Yoon HG, You Y, Kim OK, Choi KC. Water extract of Curcuma longa L. Ameliorates Non-Alcoholic Fatty Liver Disease. Nutrients. 2019:11:2536.

33. Nagavekar N, Singhal RS. Supercritical fluid extraction of Curcuma longa and Curcuma amada oleoresin: optimization of extraction conditions, extract profiling, and comparison of bioactivities. Ind Crop Prod. 2019;134:134-45

34. Schulz KF, Altman DG, Moher D. CONSORT 2010 statement: updated guidelines for reporting parallel group randomised trials. BMC Med. 2010;8:18.

35. Shiwaku K, Anuurad E, Enkhmaa B, Nogi A, Kitajima K, Shimono K, et al. Overweight Japanese with body mass indexes of 23.0-24.9 have higher risks for obesity-associated disorders: a comparison of Japanese and Mongolians. Int J Obes Relat Metab Disord. 2004;28:152-8.

36. Uchio R, Muroyama K, Okuda-Hanafusa C, Kawasaki K, Yamamoto Y, Murosaki S. Hot Water Extract of Curcuma longa L. Improves Serum Inflammatory Markers and General Health in Subjects with Overweight or Prehypertension/Mild Hypertension: A Randomized, Double-Blind, Placebo-Controlled Trial. Nutrients. 2019;11:1822.

37. Kawasaki K, Muroyama K, Yamamoto N, Murosaki S. A hot water extract of Curcuma longa inhibits adhesion molecule protein expression and monocyte adhesion to TNF-alpha-stimulated human endothelial cells. Biosci Biotechnol Biochem. 2015;79:1654-9.

38. Su JY, Tan LR, Lai P, Liang HC, Qin Z, Ye MR, et al. Experimental study on anti-inflammatory activity of a TCM recipe consisting of the supercritical fluid $\mathrm{CO} 2$ extract of Chrysanthemum indicum, patchouli oil and zedoary turmeric oil in vivo. J Ethnopharmacol. 2012;141:608-14.

39. Fukuhara S, Bito S, Green J, Hsiao A, Kurokawa K. Translation, adaptation, and validation of the SF-36 health survey for use in Japan. J Clin Epidemiol. 1998:51:1037-44.

40. Fukuhara S, Ware JE Jr, Kosinski M, Wada S, Gandek B. Psychometric and clinical tests of validity of the Japanese SF-36 health survey. J Clin Epidemiol. 1998;51:1045-53.

41. Heuchert JP. McNair DM: profile of mood states, POMS-2. North Tonawanda: Multi-Health Systems Inc; 2012.

42. Yokoyama K, Watanabe K. Translation of POMS 2: profile of mode states second edition (in Japanese). Tokyo, Japan: Kaneko Shobo; 2015.

43. Bogdanski P, Suliburska J, Szulinska M, Stepien M, Pupek-Musialik D, Jablecka A. Green tea extract reduces blood pressure, inflammatory biomarkers, and oxidative stress and improves parameters associated 
with insulin resistance in obese, hypertensive patients. Nutr Res. 2012;32:421-7.

44. Kucukerdonmez O, Rakıcıoglu N. The effect of seasonal variations on food consumption, dietary habits, anthropometric measurements and serum vitamin levels of university students. Prog Nutr. 2018;20:165-75.

45. Iwao T, Sakai K, Ando E. Seasonal fluctuations of glycated hemoglobin levels in Japanese diabetic patients: effect of diet and physical activity. Diabetol Int. 2013;4:173-8.

46. Blüher M. Obesity: global epidemiology and pathogenesis. Nat Rev Endocrinol. 2019;15:288-98.

47. Kim JH, Kim OK, Yoon HG, Park J, You Y, Kim K, et al. Anti-obesity effect of extract from fermented Curcuma longa $\mathrm{L}$ through regulation of adipogenesis and lipolysis pathway in high-fat diet-induced obese rats. Food Nutr Res. 2016;60:30428.

48. Song WY, Choi JH. Korean Curcuma longa L. induces lipolysis and regulates leptin in adipocyte cells and rats. Nutr Res Pract. 2016;10:487-93.

49. Yoshizumi T, Nakamura T, Yamane M, Islam AH, Menju M, Yamasaki K, et al. Abdominal fat: standardized technique for measurement at CT. Radiology. 1999;211:283-6.

50. Ryo M, Maeda K, Onda T, Katashima M, Okumiya A, Nishida M, et al. A new simple method for the measurement of visceral fat accumulation by bioelectrical impedance. Diabetes Care. 2005;28:451-3.

51. Sung KC. Seasonal variation of C-reactive protein in apparently healthy Koreans. Int J Cardiol. 2006;107:338-42.

52. Liu B, Taioli E. Seasonal variations of complete blood count and inflammatory biomarkers in the US population - analysis of NHANES data. PLOS One. 2015:10:e0142382.

53. Kumae T, Sugawara K, Machida K, Shimaoka A. Seasonal changes in immune function. 1. Seasonal changes in the levels of immunoglobulins, complements and some proteins. Jpn J Biometeor. 1986;23:19-27.

54. Arima H, Kubo M, Yonemoto K, Doi Y, Ninomiya T, Tanizaki Y, et al. Highsensitivity C-reactive protein and coronary heart disease in a general population of Japanese: the Hisayama study. Arterioscler Thromb Vasc Biol. 2008:28:1385-91.

55. Iso H, Noda H, Ikeda A, Yamagishi K, Inoue M, Iwasaki M, et al. The impact of C-reactive protein on risk of stroke, stroke subtypes, and ischemic heart disease in middle-aged Japanese: the Japan public health centerbased study. J Atheroscler Thromb. 2012;19:756-66.

56. Doi Y, Kiyohara Y, Kubo M, Ninomiya T, Wakugawa Y, Yonemoto K, et al. Elevated C-reactive protein is a predictor of the development of diabetes in a general Japanese population: the Hisayama study. Diabetes Care. 2005;28:2497-500.

57. Ridker PM, Cushman M, Stampfer MJ, Tracy RP, Hennekens CH. Inflammation, aspirin, and the risk of cardiovascular disease in apparently healthy men. N Engl J Med. 1997;336:973-9.

58. Mizoguchi M, Tahara N, Tahara A, Nitta Y, Kodama N, Oba T, et al. Pioglitazone attenuates atherosclerotic plaque inflammation in patients with impaired glucose tolerance or diabetes a prospective, randomized, comparator-controlled study using serial FDG PET/CT imaging study of carotid artery and ascending aorta. JACC Cardiovasc Imaging. 2011:4:1110-8.

59. Rothwell PM, Price JF, Fowkes FG, Zanchetti A, Roncaglioni MC, Tognoni $\mathrm{G}$, et al. Short-term effects of daily aspirin on cancer incidence, mortality, and non-vascular death: analysis of the time course of risks and benefits in 51 randomised controlled trials. Lancet. 2012;379:1602-12.

60. Vaishnaw AK, Mitchell TJ, Rose SJ, Walport MJ, Morley BJ. Regulation of transcription of the TATA-less human complement component C4 gene. J Immunol. 1998;160:4353-60.

61. Mizuguchi J, Hu CH, Cao Z, Loeb KR, Chung DW, Davie EW. Characterization of the $5^{\prime}$-flanking region of the gene for the gamma chain of human fibrinogen. J Biol Chem. 1995;270:28350-6.

62. Dalmon J, Laurent M, Courtois G. The human beta fibrinogen promoter contains a hepatocyte nuclear factor 1-dependent interleukin-6-responsive element. Mol Cell Biol. 1993;13:1183-93.

63. Duan $\mathrm{HO}$, Simpson-Haidaris PJ. Functional analysis of interleukin 6 response elements (IL-6REs) on the human gamma-fibrinogen promoter: binding of hepatic Stat3 correlates negatively with transactivation potential of type II IL-6REs. J Biol Chem. 2003;278:41270-81.
64. Falus A, Rokita H, Walcz E, Brozik M, Hidvégi T, Merétey K. Hormonal regulation of complement biosynthesis in human cell lines--II. Upregulation of the biosynthesis of complement components $\mathrm{C} 3$, factor $\mathrm{B}$ and $\mathrm{C} 1$ inhibitor by interleukin- 6 and interleukin-1 in human hepatoma cell line. Mol Immunol. 1990;27:197-201.

65. Sartain SE, Turner NA, Moake JL. TNF regulates essential alternative complement pathway components and impairs activation of protein $\mathrm{C}$ in human glomerular endothelial cells. J Immunol. 2016;196:832-45.

66. Rein-Smith CM, Anderson NW, Farrell DH. Differential regulation of fibrinogen $y$ chain splice isoforms by interleukin-6. Thromb Res. 2013;131:89-93.

67. Okuda-Hanafusa C, Uchio R, Fuwa A, Kawasaki K, Muroyama K, Ymamoto $Y$, et al. Turmeronol a and turmeronol B from Curcuma longa prevent inflammatory mediator production by lipopolysaccharide-stimulated RAW264.7 macrophages, partially via reduced NF-kB signaling. Food Funct. 2019;10:5779-88.

68. Testa MA, Simonson DC. Assessment of quality-of-life outcomes. N Engl J Med. 1996;334:835-40.

69. Garvin P, Nilsson E, Ernerudh J, Kristenson M. The joint subclinical elevation of CRP and IL-6 is associated with lower health-related quality of life in comparison with no elevation or elevation of only one of the biomarkers. Qual Life Res. 2016;25:213-21.

70. Lacourt TE, Vichaya EG, Chiu GS, Dantzer R, Heijnen CJ. The high costs of low-grade inflammation: persistent fatigue as a consequence of reduced cellular-energy availability and non-adaptive energy expenditure. Front Behav Neurosci. 2018;12:78

71. Liukkonen T. Low-grade inflammation in depression, Anxiety and Sleep Disturbances: University of Oulu; 2011.

72. Seiler A, Murdock KW, Fagundes CP. Impaired mental health and lowgrade inflammation among fatigued bereaved individuals. J Psychosom Res. 2018;112:40-6.

73. Cho HJ, Kivimäki M, Bower JE, Irwin MR. Association of C-reactive protein and interleukin- 6 with new-onset fatigue in the Whitehall II prospective cohort study. Psychol Med. 2013;43:1773-83.

74. Al-Hakeim HK. Serum cortisol, immunoglobulins and some complements among depressed patients. Indian J Clin Biochem. 2008;23:76-80.

75. Boix-Castejón M, Herranz-López M, Gago AP, Olivares-Vicente M, Caturla $\mathrm{N}$, Roche $\mathrm{E}$, et al. Hibiscus and lemon verbena polyphenols modulate appetite-related biomarkers in overweight subjects: a randomized controlled trial. Food Funct. 2018;9:3173-84.

76. Morita H, Ikeda T, Kajita K, Fujioka K, Mori I, Okada H, et al. Effect of royal jelly ingestion for six months on healthy volunteers. Nutr J. 2012;1 1:77.

77. Miller GE, Rohleder N, Stetler C, Kirschbaum C. Clinical depression and regulation of the inflammatory response during acute stress. Psychosom Med. 2005;67:679-87.

78. Childs E, Van Dam NT, de Wit H. Effects of acute progesterone administration upon responses to acute psychosocial stress in men. Exp Clin Psychopharmacol. 2010;18:78-86.

79. Slavich GM, Irwin MR. From stress to inflammation and major depressive disorder: a social signal transduction theory of depression. Psychol Bull. 2014;140:774-815.

80. Jin SE, Ha H, Shin HK. Effects of herbal formulas Bojungikgi-tang and Palmijihwang-hwan on inflammation in RAW 264.7 cells and the activities of drug-metabolizing enzymes in human hepatic Microsomes. J Med Food. 2018;21:1173-87.

81. Satoh N, Sakai S, Kogure T, Tahara E, Origasa H, Shimada Y, et al. A randomized double blind placebo-controlled clinical trial of Hochuekkito, a traditional herbal medicine, in the treatment of elderly patients with weakness $\mathrm{N}$ of one and responder restricted design. Phytomedicine. 2005;12:549-54.

82. Felger JC. Imaging the role of inflammation in mood and anxiety-related disorders. Curr Neuropharmacol. 2018;16:533-58.

83. Réus GZ, Fries GR, Stertz L, Badawy M, Passos IC, Barichello T, et al. The role of inflammation and microglial activation in the pathophysiology of psychiatric disorders. Neuroscience. 2015;300:141-54.

84. Hopper AT, Jones KA, Campbell BM, Li G. Neuroinflammation in mood disorders: mechanisms and drug targets. Annu Rep Med Chem. 2013:48:317-31.

85. Rosenblat JD, McIntyre RS. Efficacy and tolerability of minocycline for depression: a systematic review and meta-analysis of clinical trials. J Affect Disord. 2018;227:219-25. 
86. Kim JE, Shrestha AC, Kim HS, Ham HN, Kim JH, Kim YJ, et al. WS-5 extract of Curcuma longa, Chaenomeles sinensis, and Zingiber officinale contains anti-AChE compounds and improves $\beta$-amyloid-induced memory impairment in mice. Evid Based Complement Alternat Med. 2019;2019:5160293.

87. Xu J, Ji F, Kang J, Wang H, Li S, Jin DQ, et al. Absolute configurations and NO inhibitory activities of Terpenoids from Curcuma longa. J Agric Food Chem. 2015;63:5805-12.

88. Vasileva LV, Saracheva K, Ivanovska MV, Petrova AP, Sucouglu E, Murdjeva MA, et al. Beneficial Effect of Chronic Treatment with Extracts from Rhodiola Rosea L. and Curcuma Longa L. on the Immunoreactivity of Animals Subjected to a Chronic Mild Stress Model. Folia Med (Plovdiv). 2017:59:443-53.
89. Ibironke $G$, Alemonu O. Effects of ethanol extract of curcuma longa rhizome on Neurobehavioural activities in stressed rats. Afr J Biomed Res. 2013;16:193-7.

90. Kumar A, Singh A. Possible nitric oxide modulation in protective effect of (Curcuma longa, Zingiberaceae) against sleep deprivation-induced behavioral alterations and oxidative damage in mice. Phytomedicine. 2008;15:577-86.

\section{Publisher's Note}

Springer Nature remains neutral with regard to jurisdictional claims in published maps and institutional affiliations.
Ready to submit your research? Choose BMC and benefit from:

- fast, convenient online submission

- thorough peer review by experienced researchers in your field

- rapid publication on acceptance

- support for research data, including large and complex data types

- gold Open Access which fosters wider collaboration and increased citations

- maximum visibility for your research: over 100M website views per year

At BMC, research is always in progress.

Learn more biomedcentral.com/submissions 